$\begin{array}{r}\text { Volume and Issues Obtainable at Center for Sustainability Research and Consultancy } \\ \text { Sustainable Business and Society in Emerging Economies } \\ \text { ISSN: 2708-2172 \& (E): 2708-2504 } \\ \text { Volume 3: Issue 3 September 2021 } \\ \text { CSRᄃ } \\ \text { Journal homepage: www.publishing.globalcsrc.org/sbsee } \\ \hline\end{array}$

\title{
Agency in Computer-Assisted Language Learning (CALL): Learning to Use Language for a Sustainable Post-COVID-19 Society
}

\author{
*Riaz Hussain, Assistant Professor, Dept. of English Linguistics, The Islamia University of \\ Bahawalpur, Pakistan \\ Usman Ilyas, M.Phil Scholar, Department of English Linguistics, The Islamia University of \\ Bahawalpur, Pakistan \\ Aisha Ilyas, Associate Lecturer, Department of English Linguistics, The Islamia University of \\ Bahawalpur, Pakistan
}

Corresponding author's email address: dr.riazhussain@iub.edu.pk

\begin{tabular}{l}
\hline ARTICLE DETAILS \\
\hline History \\
Revised format: Aug 2021 \\
Available Online: Sep 2021 \\
\hline Keywords \\
Computer Assisted Language \\
Learning (CALL), Agency, \\
Integrative CALL, Real-world \\
Learning, ESL learners in \\
Pakistan, Language teaching in \\
post-COVID-19 world.
\end{tabular}

JEL Classification

Z13, Z19

\section{OPEN ACCESS}

\section{ABSTRACT}

Purpose: Against a background of educational world hampered by the pandemic of COVID-19, the current study aimed to explore ESL learners' perceptions about the potential of Computer-Assisted Language Learning in helping them create and share knowledge for a sustainable Post-COVID-191 society.

Design/Methodology/Approach: The current study followed Quantitative approach with exploratory research design. A closeended questionnaire designed and piloted by the researches was distributed among 100 ESL learners pursuing their studies at the department of English, the Islamia university of Bahawalpur and the department of English, the Government Sadiq Egerton College Bahawalpur.

Findings: The findings of the study reveal that $71 \%$ of the respondents are not aware of the novel concept of 'agency' in Computer Assisted Language Learning (CALL) and education. However, the results show that $80 \%$ of the respondents are aware of the importance of the ESL learners making linguistic, communicative and interactive contributions in real life and the potential of computer technology for sustainable L2 development.

Implications/Originality/Value: In Pakistan there have been done few studies on the aspect of "agency" in Computer Assisted Language Learning (CALL). The findings imply that since most of the learners are unaware of the concept of "agency" in CALL, therefore, ESL teachers should acquaint ESL learners not only with the dynamic concept but also with the novel practical applications of the concept.

(C) 2021 The authors, under a Creative Commons AttributionNonCommercial- 4.0

Recommended citation: Hussain, R., Ilyas, U. \& Ilyas, A. (2021). Agency in Computer-Assisted Language Learning (CALL): Learning to Use Language for a Sustainable Post-COVID-19 Society. Sustainable Business and Society in Emerging Economies, 3(3), 397-409. 


\section{Introduction}

Traditionally, a sustainable society is a society in which energies are not misused, environment is not damaged and resources are not overworked. Coomer (2014) argues that human quest for a sustainable society entails a continual evaluation of political, social and economic aspects. Thus, in the postCOVID-19 world we need to redefine our sustainable society amid newer fears. The same is the case with sustainable learning. Usually, a sustainable learning is learning in which healthy learning takes place and knowledge is co-created and shared in the community. In this type of learning, teachers and educationists are self-reflective and adoptive to the transformations taking place. In this background, the concept of agency in Computer-Assisted language learning offers us tools and insights with which we can translate into practice the concept of sustainable learning. The importance of these soft tools gained momentum in the wake of COVID-19 pandemic. The world witnessed how schools, colleges and universities were closed and students had to learn from their homes. The threat of pandemics still looms large on us. Hence, there is a need to stand with the newer definitions of sustainable society and sustainable learning in the post-COVID-19 world. While the world intellectuals try to find new definitions of sustainable society flanked by viruses and pandemics, it is the duty of linguists to find newer tools of language learning and teaching. Amjid, Hussain \& Siddiq (2020) and Asgher and Hanif (2021) have already discussed the importance of digital technologies for language teaching and learning in Pakistan in the pre-COVID-19 and post-COVID-19 world. But, still there is need to further explore the topic from the perspective of agency in Integrative CALL.

The use of latest technologies in the classroom offers interesting opportunities for the learners to construct meaningful connections with the real-world. Integrating the connections of the outside realworld with the learning plan, assist the students to make sense of their learning. In this way they can realize why and what they are actually learning and how this learning can be valuable outside the classroom. This approach is suitable for every single curriculum in order to enhance engagement in the process of learning as learners acquire helpful insights into real life applications of the skills they are being taught.

Learning a second or a foreign language is not an easy task, however, technology has revolutionized the process of second language learning (Levy, 2009). Technology has transformed the way we acquire languages. Gone are the days of pouring over textbooks and massive bilingual dictionaries to learn a second language. There is a paradigm shift in the instruction framework of second language learning with the use of multitudinous tools and latest technology. Innovation in the field of language learning has propelled the learners as well as the instructors to shift from the traditional methods of language learning towards more advanced and learner-centered approaches. In the learners-centered approaches to language learning more focus and attention is given to the autonomy and self-sufficiency of the leaners by connecting learning to the real-life situations. Connecting classroom learning with real life can encourage creativity, enhance learning and make students independent leaners. By linking classrooms to the globe, educators can show the significance of topics and provide learners with a vision of what is feasible-offering a useful structure for educational and personal growth.

Computer-based language learning operations provide a wealthy context for organized learning and alternative techniques of teaching. Bringing content to life through textual and images means such as podcasts, newsfeeds, and video streaming, connects the classroom to a wider globe. Interactive technology in education promotes the active participation of the students and they can regulate their own learning by empowering themselves with the latest language learning tools and by taking notice of what is happening in their surroundings. Taking advantage of latest technology is a good approach to ignite student's willingness to learn language across their all academic levels. By using the technology ESL learners can practice their own learning independently thus, achieving high language proficiency.

The concept of agency occupies a central position in instructional studies. The idea behind agency is that 
that education should enable the learners to become self-sufficient and independent thinkers, forms the basis for self-directed action. This concept has a profound impact on recent educational theories and practices. In the past few years, there was a serious debate regarding learner-centric approaches to education. These all aspects are linked with the notion of learner but the notion of agency goes deeper than this.

\section{Agency in Education}

Society imparts education to children for better development of society. According to Biesta and Tedder (2007), the root of the term 'agency' can be found in legal and commercial register. In legal and commercial language, a difference is drawn between "principal" and "agent". In legal and commercial discourse, agent is granted the capacity to act autonomously on behalf of the principal. Furthermore, in social sciences, agency is defined as 'the capacity for independent social action' or 'the capability to work autonomously of restraints of social structure' (Biesta and Tedder, 2007). Let us further explore the idea further in the light of opinion of experts.

"Agency is the capacity to act in the world." (Heuman, 2014). Heuman refers to capacity to meet challenges in real world. 'Agency can be defined as 'the sociocultural mediated manner to act' (Ahearn, 2001). It means society and culture play their role in preparing an individual for his/her contribution in society.' 'Individual agency - the capability to create, produce, or generate and make a significant difference in societal practices.' (Stetsenko, 2005). Agency is one of the most basic and essential trait of universal human behavior and it has been defined as an individual's determination and ability to act (Gao, 2010). Agency refers to the ways people act and interact within sociocultural settings (Blair, 2009). Agency is, according to Bruner (1996), 'captivating more control of one's own mental activity' (p. 87). The capability and aptitude to make choices, to make use of various approaches, and to generate frames that allow understanding are 'key concepts of the agentive approach to mind' (p. 93). Moreover, Swanwick (1999) explicates on Bruner's concepts, explaining agency as 'the natural drives that endures spontaneous learning: inquisitiveness; a yearning to be competent; a desire to outdo others and a requirement for social interactions'.

In the field of education, learners' ability to work independently seems to have always been the priority of educationists in making educational policies, designing curriculum, designing teaching learning materials and setting educational goals. Biesta and Tedder (2007) find the origin of agency in education in the enlightenment and in the views of Immanuel Kant. According to Elder, Kirkpartrick \& Crosnoe (2003), the notion that education should support people in developing their aptitude and abilities for agented and self-directed act has been a deep-rooted philosophy in Western societies since the age of Enlightenment. In this background, the researchers tried to find out the answer of the following research question.

\section{Research Question}

1. What are learners' perceptions about "Agency" in Computer Assisted Language Learning (CALL) and its different aspects?

Since agency in integrative CALL is related to computer-based language teaching, the researchers thought it germane to focus on technology and language in sieving the literature.

\section{Literature Review}

In the following the researchers give review of relevant literature. The literature relevant to the abovementioned question focuses on origin and development of CALL.

\section{What Is Call?}

CALL is defined as "the quest for and study of applications of the computer in language learning and teaching” (Levy, 1997: 1). The fundamental point of CALL is to discover approaches to utilize 
computers for the purpose of language learning using interactive media, CD-ROM, Software packages and web applications. CALL is differently known as Computer-Assisted Language Instruction (CALI), Computer-Aided Language Learning (CALL), and Computer-Enhanced Language Learning (CELL). The initial two terms for the most part allude to computer applications in language learning and instructing.

\section{Importance of Call}

CALL has restructured the process of language learning. It would now be said that Computer Aided Language Learning has become the new normal and that we are currently entering a completely coordinated and naturalized period of CALL (Reinders and Thomas, 2012). CALL has advanced into the standard instructing of Language learning, broadly and globally, and the eventual fate of CALL is straightforwardly identified with language education (Hubbard, 2008). Various researchers found that learners utilizing CALL have performed better as compared to their fellows who never made use of CALL (Chapelle, 2001; Warschauer, 1997).

Bush (2008) concludes that computer not only facilitate teachers in language teaching but also aids students in learning the language. Modern technology has changed the traditional teaching methods as well learning techniques. It has transformed the learning methods from the traditional approaches to more modern techniques where students can learn the language in a comfortable environment with games, activities and hand-on practices. These modern learning approaches enable the students to practice their target language in situations that re-create real-life situations (Bush, 2008).

There are countless reasons why ELT instructors should use CALL. According to Pennington and Steven (1992), computers can share exercise skills by making educators more proficient and give extraordinary help to the student even without the nearness of the instructor. New advancements have seen computers quicker, and simpler for the instructor to utilize. According to Felix (1998), advancements enable computers run sight and sound applications, fusing video, sound, and content, and this limit enables the student to interface with both the program and other learners. Moreover, computer offers incredible adaptability for the pacing of picking exercises and substance to suit individual learning styles (Levy, 2009).

\section{Agency in Call}

The fundamental aim of integrative CALL is to foster the learner's agency (Warschauer, 1996). In the present study the term "agency" is taken as "the ability of individual beings to make choices and act on these choices in a way that makes a difference in their lives" (Martin, 2004, p.135) and which is socioculturally, contextually and interpersonally mediated (Mercer, 2011). In order to carry out intentional actions, learners can use their motor and/or sensory systems (Bandura, 1999) and/or language (Austin, 1962). Pedagogical activities, like information-gap, role-plays or quests are performed with technology. These tasks involve learners to receive or articulate language (both spoken and written) and also intercede with several visual, textual and audio screen-based resources.

Agency includes the learner's initiative or self-regulation. Before learners can practice agency in their own specific learning contexts, they are supposed to believe that their behavior and learning strategy will actually make a difference for them in language learning. Moreover, agency is symbiotic. It mediates and is mediated by the sociocultural context of the classroom. It does not mean that learners are alone and they are doing whatever they want to do or whatever suits them. Learners must have the awareness that their choices and decisions may have the consequences (levy, 1997). Furthermore, agency also includes the awareness of the fact that learners should be able to take responsibility of their own actions on the surroundings and on others. So, there's a social connectedness kind of dimension to every choice a learner makes and every action she or he takes will have an effect on other people's thinking, behavior or choices and vice versa. 


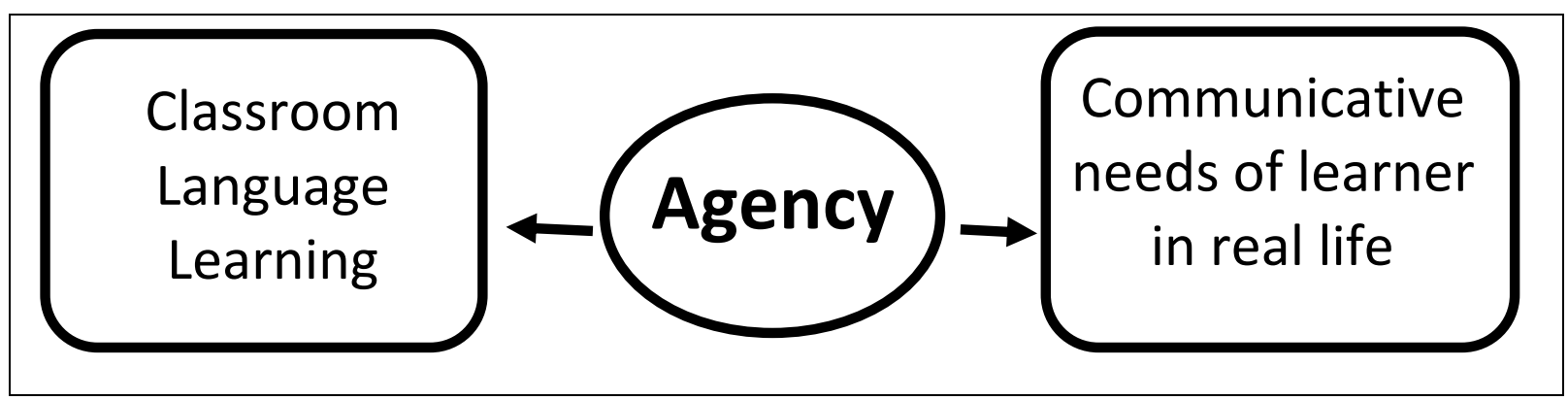

Figure 1. Agency; connecting learning to real life.

\section{Research Methodology}

The following paragraphs discuss important points of research design, research methods and data analysis tools followed and used in this study.

\section{Design of the Study}

Research design is a framework of methods and techniques chosen by any researcher to connect the different components of research in a logical manner so the research question can be effectively addressed. It offers perspectives on how to conduct research using a specific methodology. The research design of this particular study is non-experimental and simple exploratory at the same time.

\section{Methods}

This study employed a quantitative research approach as it made use of the principles of quantitative approach, therefore; a quantitative tool i.e. close ended questionnaire was used to acquire more objective and generalizable results.

\section{Selection of the Population for the Study}

The concept of agency seems to contain elemental interactivity. Therefore, learners with better learning were required for this study. In this context, researchers selected MA level because their learning abilities seem to be far better than the learning of intermediate and graduation levels of students. Population of this study includes students of MA English studying at The Islamia University of Bahawalpur and Government S.E College Bahawalpur.

\section{Data Collection Tool}

Data collection tools are the pillars of any research study, so to speak. A questionnaire comprising of close-ended questions was used in this study to gather the desired data. This tool had a two-fold benefit for the researchers. Primarily, maximum amount of data was gathered in a short time span. Furthermore, this tool helped the researchers to control the irrelevant variables. Hence, make the results more reliable and valid. The data was collected from 100 students. The questionnaire was designed in simple and easy language so that the participants could fill it easily.

\section{Data Analysis}

In this research, quantitative approach was followed by the researchers to collect the data. The gathered quantitative data was then analyzed in order to arrive at the findings with the help of SPSS version 22; calculating percentage, frequency, valid percent, and cumulative percent. The significant variables in the demographic information included age and gender. The reliability and validity of the questionnaire was considered important and determined by using SPSS version 22. The reliability of questionnaire was $87.3 \%$. 


\begin{tabular}{|l|l|}
\hline \multicolumn{2}{|l|}{ Reliability Statistics } \\
\hline Cronbach's Alpha & Number of Items \\
\hline .873 & 53 \\
\hline
\end{tabular}

Table.1. Reliability of Questionnaire

\section{Results and Discussion}

The following graphs show the finds of the study. They contain frequencies of responses of the ESL learners who participated in the research.

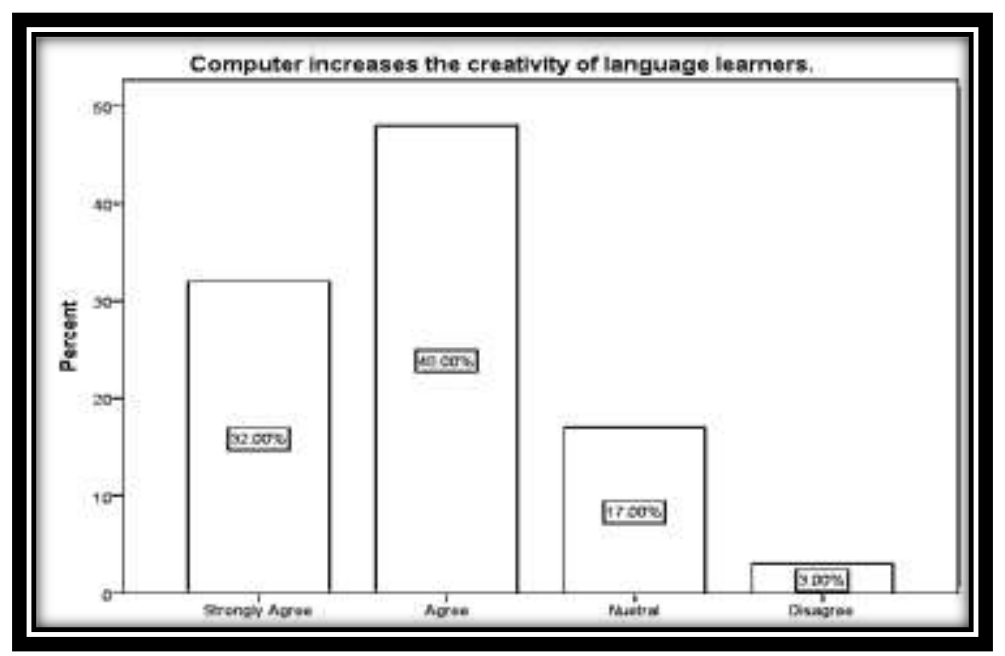

Figure. 2. Computer increases the creativity of language learners

Computer not only enhances the learning skills of the students but it also helps in creating new ideas and thoughts among the language learners of different age which is directly related with creativity. Out of 100 respondents, $32 \%$ of respondents strongly agreed, whereas, $48 \%$ agreed, $17 \%$ were neutral and $3 \%$ of the respondents disagreed to the statement. Basic aim behind this query is to check interest of language learners towards computer learning.

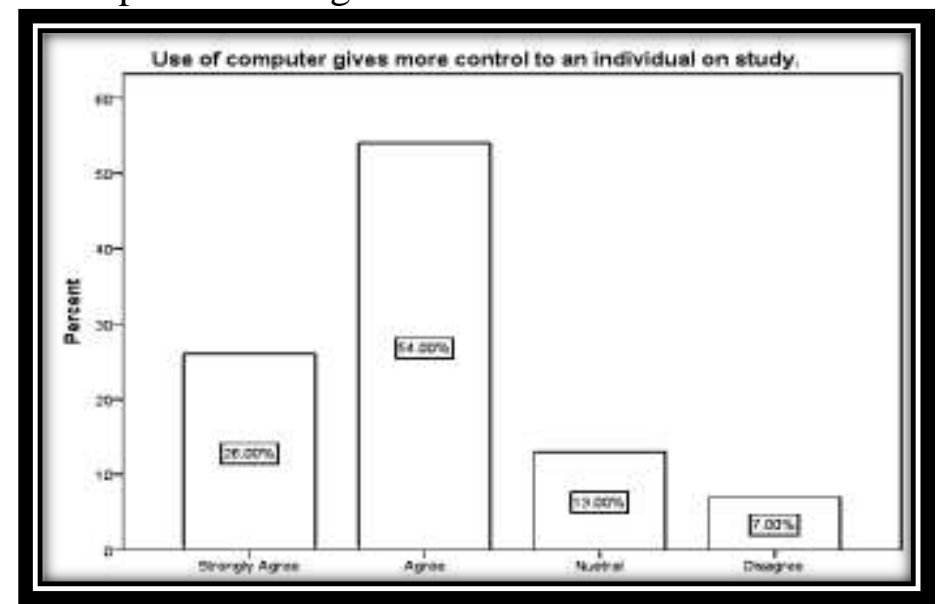

Figure. 3. Use of computers give more control on Study 
Use of computer is increasing with the passage of time in all the domains of language learning. Primary reason behind this question is to investigate if computers provide more control to its users. The analysis of the questionnaire showed that $26 \%$ of the respondents strongly agreed while $54 \%$ of the respondents agreed. Moreover, $13 \%$ of the total respondents were neutral and $7 \%$ showed disagreement. The responses show that the usage of computer gives more control to individuals in learning.

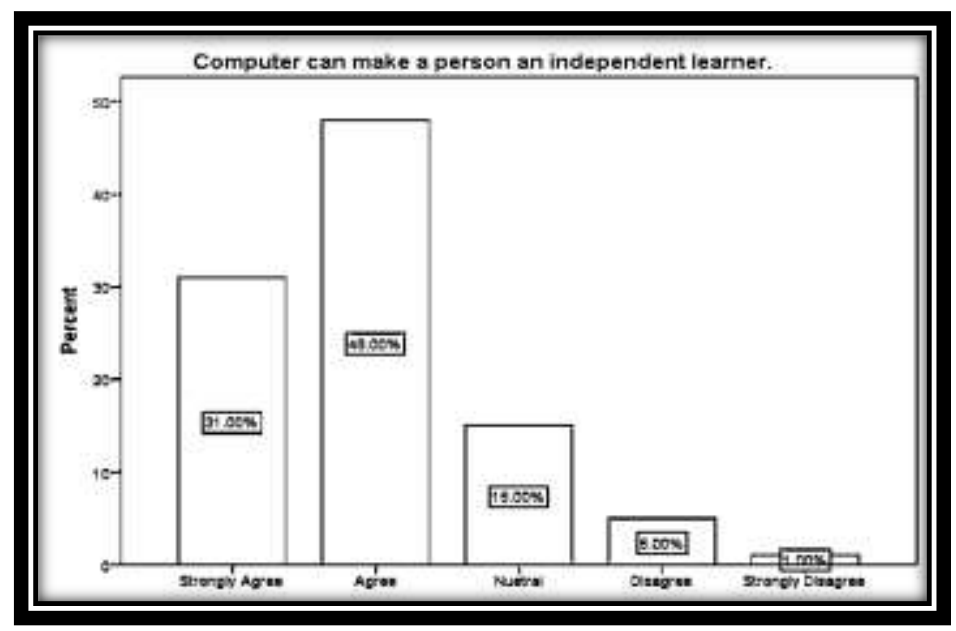

Figure 4. Computers can make independent learners

With computers in hand, learners become responsible for their own learning and they experience a great deal of autonomy and independence. When asked about the role of computers in making students independent; $31 \%$ of respondents strongly agreed whereas, $48 \%$ agreed to the above statement. $15 \%$ of respondents were neutral, $5 \%$ chose "disagree" and only $1 \%$ of the total respondents strongly disagreed to the above statement.

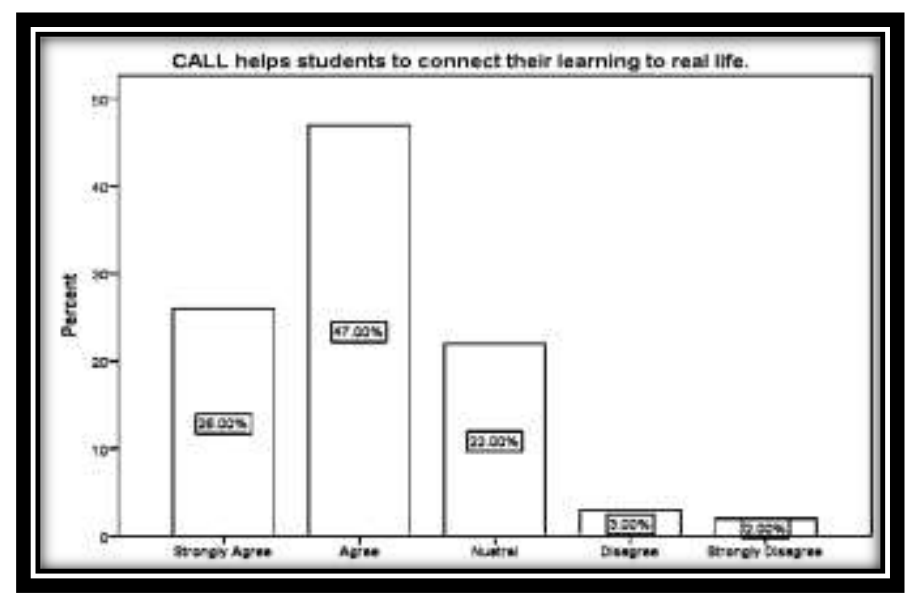

Figure. 5. CALL helps students to connect their learning to real life

When the learners were asked if Computer-Assisted language learning (CALL) aids them in relating their learning to the outside real life. $26 \%$ of respondents chose "strongly agree", $47 \%$ agreed, $22 \%$ of the respondents were neutral, $3 \%$ disagreed whereas, only $2 \%$ of the respondents strongly disagreed to the above statement. The response rate shows that a majority of respondents thought that CALL helped them to connect their learning to the real life. 


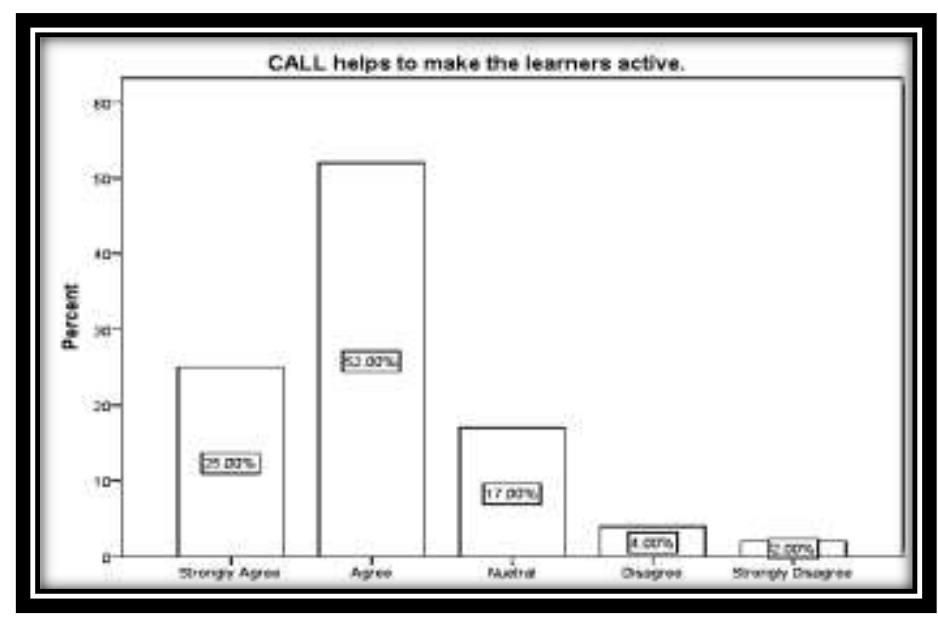

Figure. 6. Call helps to make learners active

When the learners were asked if Computer-Assisted language learning helps them become active they shared the following responses; $25 \%$ of the respondents selected "strongly agree", $52 \%$ of them agreed, $17 \%$ remained neutral and $2 \%$ disagreed. The responses imply that CALL is useful for learners in so many ways as it aids in learners become active.

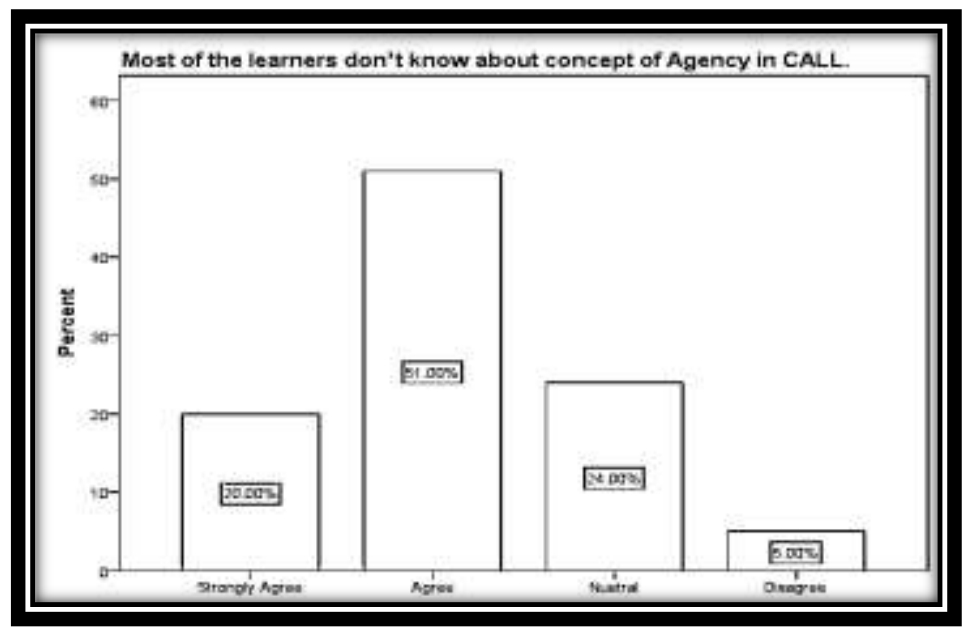

Figure. 7. Leaners do not know about the concept of Agency

The term "agency" in the integrative CALL is new for most of the respondents who filled the questionnaire. The responses show that at the time of the filling out of the questionnaires the respondents didn't know about the concept of agency. When researchers asked them about it, only $20 \%$ of the total respondents strongly agreed to the statement, $51 \%$ of them agreed, $24 \%$ were neutral and remaining $5 \%$ disagreed to the statement. 


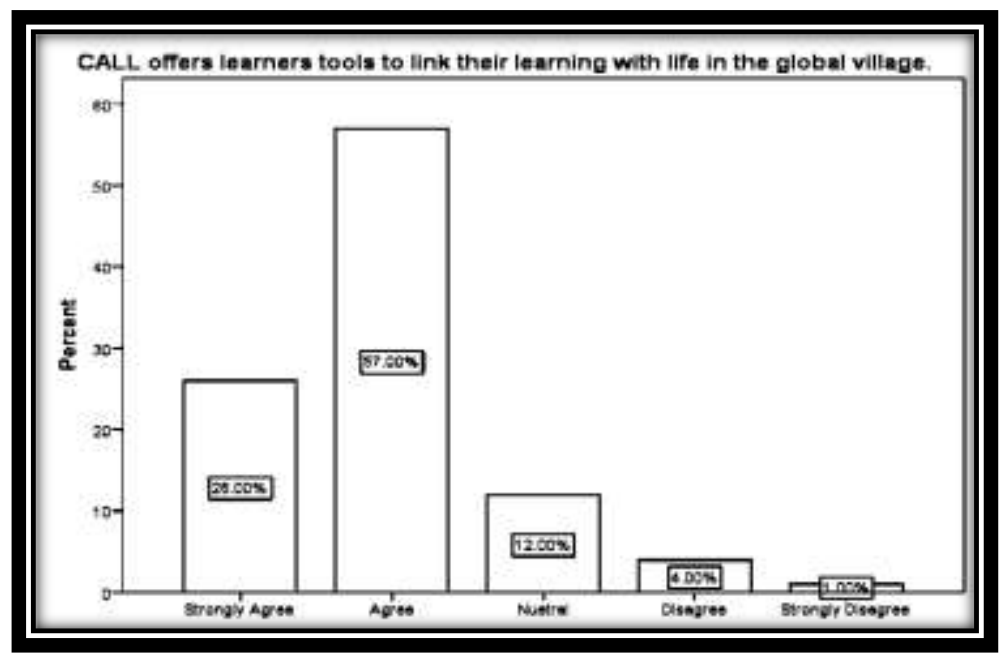

Figure. 8. CALL offers tools to link the learning with real life.

Integrative CALL helps and motivates learners, at the same time, CALL offers tools to learners so that they can connect their learning with the real life in the global village. Respondents shared the following responses as it can be seen in the figure $8 ; 26 \%$ of the respondents chose "strongly agree", $57 \%$ of the respondents agreed, $12 \%$ of the respondents remained neutral and $4 \%$ of the respondents disagreed to the statement.

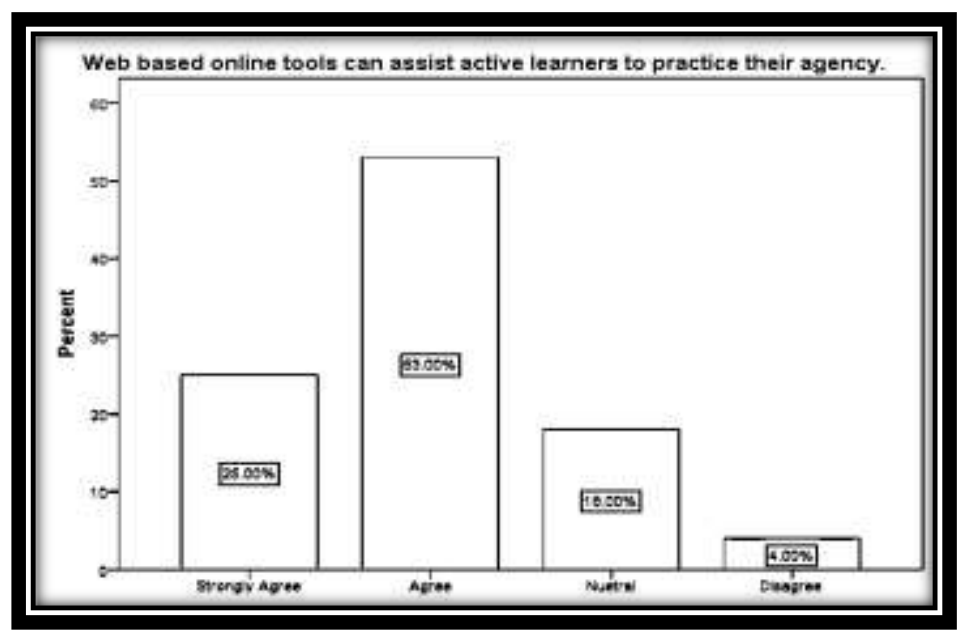

Figure 9. Web Based online tools can assist active learners to practice their agency

Active learners are more autonomous and self-sufficient therefore, there are so many online web-based tools are present that can help active learners to practice their agency. Learners were asked about the statement if web based online tools could assist active learners to practice their agency. In response of this question, $25 \%$ of the respondents opted "strongly agree", 53\% of the respondents selected "agree", $18 \%$ remained neutral and $4 \%$ of the learners disagreed to the statement. 


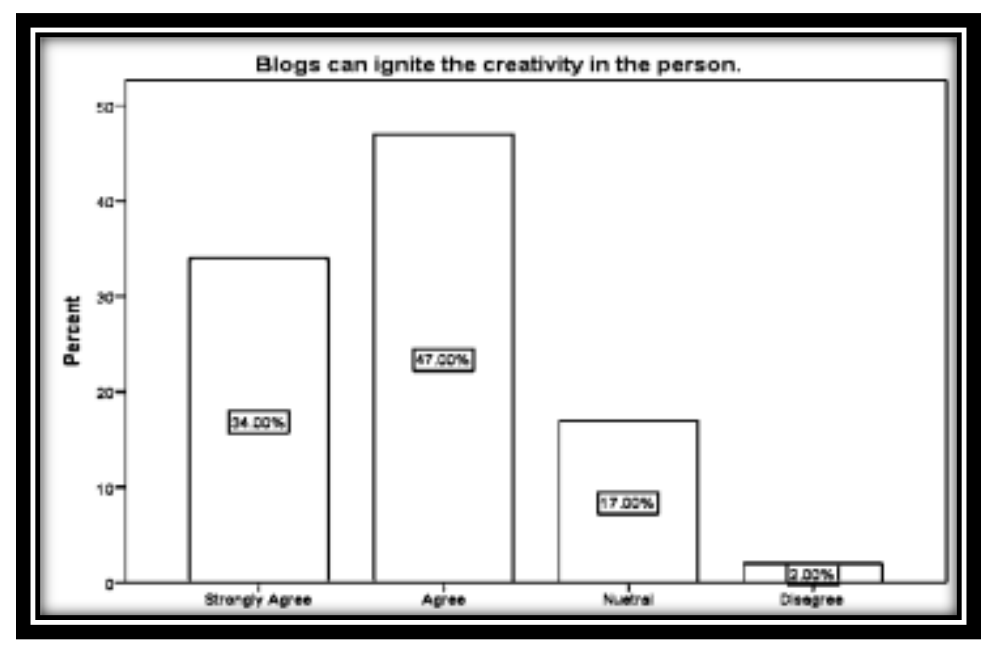

Figure10. Blogs can ignite the creativity in the person

Weblogs are the pages on the internet that can motivate and arouse interest among leaners. It can ignite the element of creativity in the learners. Learners were asked if blogs could ignite the creativity in the person. In response of this question, 34\% of the respondents opted "strongly agree", $47 \%$ of the respondents selected "agree", $17 \%$ remained neutral and only $2 \%$ of the learners disagreed. A majority of the respondents believed that blogs increase productivity and creativity of the language learners.

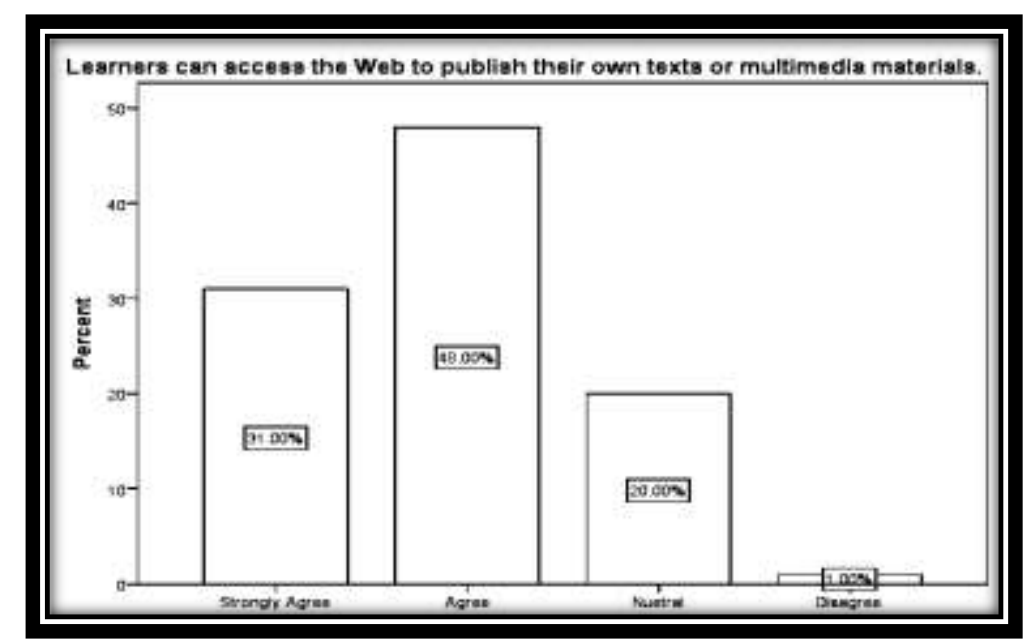

Figure11. Learners can access the Web to publish their own text.

Learners can access the internet any time to advertise their work, text and the multimedia. Learners were asked for their responses about the statement; "Learners can access the web to publish their own texts or multimedia materials". In response to the above statement, $31 \%$ of the respondents opted "strongly agree", $48 \%$ of the respondents selected "agree", $20 \%$ remained neutral and $1 \%$ of the respondents disagreed to the statement. 


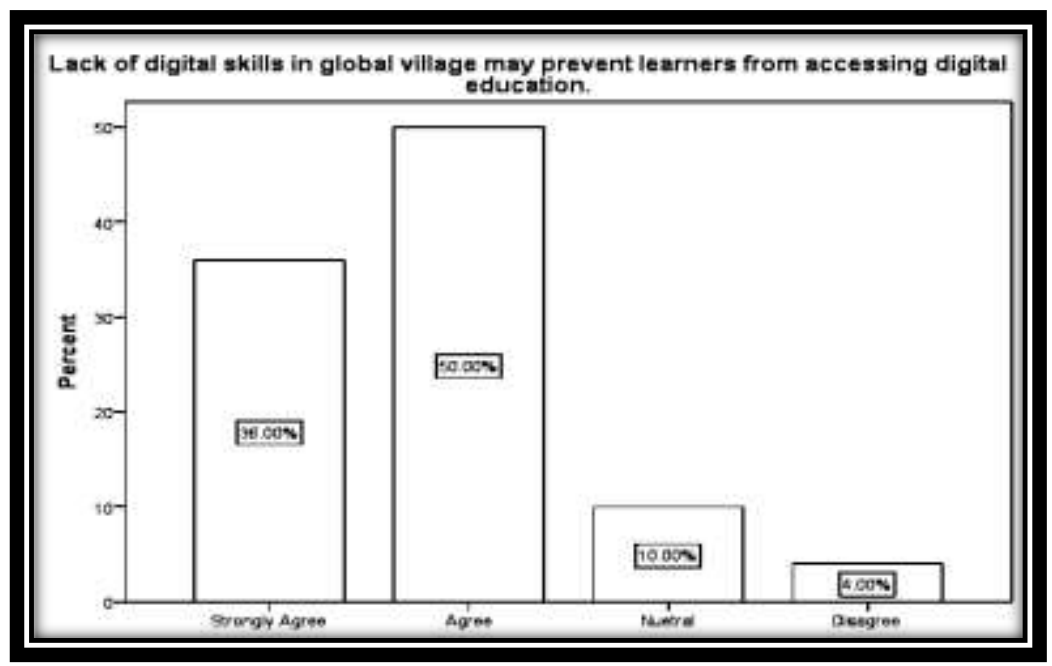

Figure12. Lack of Digital Skills preventing learners from accessing digital education.

Lack of any skill may cause a serious issue for a learner similarly if a learner has limited digital skills so there is a chance that lack of these skills may stop him from accessing digital education. In response of this statement, $36 \%$ of the respondents selected the "strongly agree" and $50 \%$ of them agreed and "neutral" was selected by $10 \%$ and $4 \%$ selected "disagree".

\section{Conclusion}

Sustainable learning prepares learners for productive contribution in society. In sustainable leaning, knowledge is co-created and shared in society. Agency helps us realize the concept of sustainable learning in the post-COVID-19 world.

This study focused on learners' perceptions about their own independence in learning, connecting classroom learning with real life, and contributing to their culture and society linguistically. The concept of agency in education and CALL refers to learner's ability to make contribution in real life. In Pakistan, little research has been done on this aspect of integrative CALL--agency. In this context, a questionnaire was designed to know about learners' perceptions about the potential of CALL to connect classroom learning with the real life or the aspect of agency.

$71 \%$ of the respondents didn't know about the concept of agency at the time of filling out of the questionnaire. $86 \%$ of the respondents believed that lack of digital skills in global village might prevent them from accessing digital education. The learners were also aware of the importance of CALL in creating links between classroom and real-life. Lack of digital skills, in this digital post-COVID-19 age, means staying away from the latest information. $87 \%$ of the respondents thought that learners' contribution in knowledge should be for the public. $78 \%$ of the respondents believed that internet offered platform for publishing their own views and text. $81 \%$ of the respondents were of the view that Blogs could provide them with medium to produce their own creative stuff. $83 \%$ of the respondents agreed that CALL offered them tools to learners to link their learning to the real life. $69 \%$ of the respondents were of the opinion that CALL helped to make learners active. $83 \%$ of the respondents were of the view that CALL helped students to link the learning with real life. $80 \%$ of the respondents agreed that use of computer gave them more control on their studies. 50\% of the respondents maintained that computer enhanced the creativity of the learners. $92 \%$ of the respondents were of the opinion that computer offered platform for better language practices. The learners believed that computer could be used not only for language learning but it can also be used for connecting to real life.

Thus, the ESL learners have positive perceptions about the potential of CALL in helping them make linguistic and communicative contributions for a sustainable post-COVID-19 society. The findings imply that ESL teachers should acquaint ESL learners not only with the dynamic concept but also with the novel practical applications of the concept. 


\section{References}

Ahearn, M. L. (2001). Language and agency. Annual Review of Anthropology, 30, 109-137. http://dx.doi.org/10.1146/annurev.anthro.30.1.109

Amjid.M, Hussain.R, Siddiq.S. (2020). Pakistani ESL Learners on the Internet: Explorations into Factors Influencing their Online Language Learning Behaviour. Global Language Review, V(III),151-162, doi: http://dx.doi.org/10.31703/glr.2020(V-III).16

Asgher, T., \& Hanif, A. (2021). Exploring the Impact of Online Teaching Method on Higher Education during COVID-19 Pandemic: Students' and Teachers' Perspective. Research Journal of Social Sciences and Economics Review, 2(1), 120-134. https://doi.org/10.36902/rjsser-

Austin, J. L., (1962). How to Do Things with Words. Oxford: Oxford University Press.

Bandura, A., (1999). A Social cognitive theory of personality. In: L. Pervin and O. John, eds. Handbook of personality: Theory and research. New York, NY: Guilford Publications. pp.154-196.

Biesta, G., \& Tedder, M. (2007). Agency and learning in the life course: Towards an ecological perspective. Studies in the Education of Adults, 39(2), 132-149. https://doi.org/10.1080/02660830.2007.11661545

Blair, D. (2009). Learner agency: To understand and to be understood. British Journal of Music Education, 26(2), 173-187. DOI:10.1017/S0265051709008420

Bruner, J. (1996). The Culture of Education. Cambridge, MA: Harvard University Press

Bush, M. D. (2008). Computer-assisted language learning: From vision to reality. CALICO Journal, 25(3), 443- 470. https://journals.equinoxpub.com/CALICO/article/viewFile/23090/19096

Coomer. J.C. (2014). The nature of the Quest for a Sustainable Society. In Coomer, J. C. (Ed). Quest for a Sustainable Society: Pergamon Policy Studies on Business and Economics. Saint Louis: Elsevier Science.

Chapelle, C., (2001). Computer applications on second language acquisition: Foundations for teaching, testing and research. Cambridge: Cambridge University Press.

Elder, G. H., Kirkpartrick Johnson, M. and Crosnoe, R. (2003) The emergence and development of lifecourse theory, in Jeylan, T., Mortimer, and Michael, J. (eds) Handbook of the Lifecourse. New York: Kluwer Academic/Plenum

Felix, U. (1998). "Towards meaningful interaction in multimedia programs for language teaching." In ON-CALL, The University of Queensland, Australia, 12(1). 20-29.

Gao, X. A. (2010). Strategic language learning: The roles of agency and context. Multilingual Matters.

Heuman, L. (2014). The embodied mind: An interview with philosopher Evan Thompson. Accessed 27 December 2017 at https://tricycle.org/magazine/embodied-mind/Tricycle, Fall issue.

Hubbard, P. (2008). Twenty-five years of theory in the CALICO Journal. CALICO Journal, 25(3), 387399.

Levy, M. (1997). CALL in context I: A historical perspective. In M. Levy. Computer Assisted Language Learning: Context and Conceptualization (pp. 13-46). Oxford University Press: New York, NY.

Levy, M. (2009). Technologies in use for second language learning. The Modern Language Journal, 93, 769-782.

Martin, J., (2004). Self-regulated learning, social cognitive theory, and agency. Educational Psychologist, 39(2), p.135-145.

Mercer, S., (2011). Understanding learner agency as a complex dynamic system. System, 39(4), p.427436.

Pennington, M.C. \& Stevens V. (eds.) (1992). Computers in Applied Linguistics. Clevedon, UK: Multilingual Matters.

Reinders,H., Hubbard,P.(2012).CALL and autonomy: affordance and constraints. in M. Thomas, H. Reinders \& Warschauer (Eds), contemporary CALL (pp359-375).

Stetsenko, A. (2005). Activity as object-related: Resolving the dichotomy of individual and collective planes of activity. Mind, Culture, and Activity, 12, 70.

Swanwick, K. (1999) Teaching Music Musically. New York: Routledge, pp. 53-4.

Warschauer M. (1996). Computer assisted language learning: An Introduction. In Fotos S. (ed.), 
Multimedia language teaching (pp.3-20), Tokyo: Logos International. Retrieved from http://www.ict4lt.org/en/warschauer.htm

Warschauer, M. (1997). Computer-mediated collaborative learning: Theory and practice. The Modern Language Journal, 81(4), 470-481.

Van Lier, L. (2008). Agency in the classroom. In J. P. Lantolf \& M. E. Poehner (Eds.), Sociocultural theory and the teaching of second languages (pp. 163-186). London: Equinox 